Article

\title{
Preparation of Readily-to-Use Stilbenoids Extract from Morus alba Callus Using a Natural Deep Eutectic Solvent
}

\author{
Jukrapun Komaikul ${ }^{1}$, Supachoke Mangmool ${ }^{2}$, Waraporn Putalun ${ }^{3}$ and Tharita Kitisripanya ${ }^{4, * \mathbb{C}}$ \\ 1 Center for Vaccine Development, Institute of Molecular Biosciences, Mahidol University, \\ Nakhon Pathom 73170, Thailand; jukrapun.kom@mahidol.ac.th \\ 2 Department of Pharmacology, Faculty of Science, Mahidol University, Bangkok 10400, Thailand; \\ supachoke.man@mahidol.ac.th \\ 3 Faculty of Pharmaceutical Sciences, Khon Kaen University, Khon Kaen 40002, Thailand; waraporn@kku.ac.th \\ 4 Department of Pharmacognosy, Faculty of Pharmacy, Mahidol University, Bangkok 10400, Thailand \\ * Correspondence: tharita.kit@mahidol.edu
}

Citation: Komaikul, J.; Mangmool, S.;

Putalun, W.; Kitisripanya, T.

Preparation of Readily-to-Use

Stilbenoids Extract from Morus alba Callus Using a Natural Deep Eutectic

Solvent. Cosmetics 2021, 8, 91

https://doi.org/10.3390/

cosmetics 8030091

Academic Editor: Antonio Vassallo

Received: 13 August 2021

Accepted: 18 September 2021

Published: 19 September 2021

Publisher's Note: MDPI stays neutral with regard to jurisdictional claims in published maps and institutional affiliations.

Copyright: (c) 2021 by the authors. Licensee MDPI, Basel, Switzerland. This article is an open access article distributed under the terms and conditions of the Creative Commons Attribution (CC BY) license (https:// creativecommons.org/licenses/by/ $4.0 /)$

\begin{abstract}
The consumer and cosmetic industries have recently placed a greater emphasis on ecofriendly solvents for botanical extraction, including natural deep eutectic solvents (NADES). In this study, NADES were prepared for Morus alba callus extraction. The efficiency of extraction from the NADES and methanol was investigated by comparison of the stilbenoids yield and antimelanogenesis activity. Prior to testing the irritability of a suitable NADES on the reconstructed human epidermis (RhE), the effect of the selected NADES on stilbenoids stability was determined. The results showed that the highest yields of stilbenoids were obtained from choline chloride-glycerol mixtures (Ch1G2) and methanol extracts, with no significant difference in yields (5.06 \pm 0.05 and $6.32 \pm 0.40 \mathrm{mg} / \mathrm{g}$ callus dry weight, respectively). The NADES extracts of M. alba callus showed comparable anti-melanogenesis activity compared to methanol. In term of stability, stilbenoids in Ch1G2 remained stable after six months of storage at $4{ }^{\circ} \mathrm{C}$ except resveratrol. Furthermore, Ch1G2 had no irritation effect on RhE. Thus, based on the findings of this study, Ch1G2 is an intriguing green solvent alternative for the extraction of $M$. alba callus and may be advantageous for the preparation of skin-lightening cosmetics.
\end{abstract}

Keywords: natural deep eutectic solvent; Morus alba; stilbenoids; stability

\section{Introduction}

Extraction is a critical step in the process of obtaining phytochemicals from plant raw materials. Typically, an organic solvent such as ethanol has been used to extract plant raw materials for cosmetic ingredients. Following extraction, the solvent should be removed or reduced using an efficient system. Organic solvent extracts in cosmetics could cause an unsatisfactory experience for consumers and may occasionally be incompatible with other cosmetic ingredients. Besides the conventional solvent, green solvents are gaining popularity as an environmentally friendly and safe alternative that benefits both workers and consumers. Exploring green solvents for the preparation of botanical extracts is a current research trend [1].

Since 2003, deep eutectic solvents (DES) have been recognized as a novel class of sustainable solvents. DES are produced from the mixing of two or more inexpensive, biodegradable components [2]. When the DES is composed entirely of primary metabolites, such as amino acids, organic acids, sugars, or choline derivatives, it is referred to as a naturally occurring deep eutectic solvent (NADES) [3]. NADES exist around cells' membranes and are involved in the biosynthesis, solubilization, and storage of a variety of poorly water-soluble and unstable compounds in cells [4]. This generates a plethora of application possibilities for NADES. Numerous studies have demonstrated that NADES are an outstanding and promising solvent choice for sustainable and green extraction, 
resulting in novel applications in the food, cosmetic, and pharmaceutical industries [5-9]. This could have the advantages of reducing the use of organic solvents and making the extract safe for use in cosmetic formulations without the need to remove the solvents [10]. Moreover, NADES are compatible with various cosmetic ingredients and may increase the extract's bioavailability [11,12].

For example, choline chloride-based NADES are commonly mixed as a hydrogen bonding acceptor for a broad spectrum of phytochemical extraction. In a previous study, the mixture of choline chloride and glycerol has been reported to be a good system for extraction of resveratrol from peanuts [13] The information from this study may further applied to the extraction of stilbenoids from other plants.

Another alternative sustainable strategy in cosmeceuticals is to use biotechnology to circumvent the limitations of natural plant sources for large-scale use. For instance, the culture conditions for $M$. alba callus were studied in order to obtain a high yield of stilbenoids in a methanolic extract with a skin lightening effect [14]. By combining this controllable source of $M$. alba with NADES extraction, a new sustainable method for producing a cosmetic ingredient might be achieved.

The purpose of this study was to determine the capacity of NADES to extract stilbenoids from M. alba callus and the suitability of a selected NADES for the preparation of the ready-to-use extract for skin lightening products.

\section{Materials and Methods}

\subsection{Chemicals and Reagents}

Mulberroside A, oxyresveratrol and resveratrol ( $>98 \%$ purity) were purchased from ChemFaces (Hubei, China). Choline chloride, sucrose, malic acid and oxalic acid were purchased from Himedia (Mumbai, India). B16-F10 (CRL-6475), Dulbecco's modified Eagle's medium (DMEM) and fetal bovine serum (FBS) were purchased from ATCC (Manassas, VA, USA). $\alpha$-Melanocyte-stimulating hormone ( $\alpha$-MSH), kojic acid, and synthetic melanin were purchased from Sigma-Aldrich (St. Louis, MO, USA). EpiSkin ${ }^{\mathrm{TM}}$ reconstructed human epidermis $\left(0.38 \mathrm{~cm}^{3}\right)$ and maintenance medium were purchased from EpiSkin (Lyon, France). All the other reagents were analytical grade.

\subsection{Plant Materials}

M. alba callus subcultured in Murashike \& Skoog medium supplemented with thidiazuron $(0.1 \mathrm{mg} / \mathrm{L})$ and naphthaleneacetic acid $(1 \mathrm{mg} / \mathrm{L})$ [14]. After 5 weeks, the callus was collected and dried at $50 \pm 5{ }^{\circ} \mathrm{C}$ for $24 \mathrm{~h}$. The dried callus was ground to powder and kept in the refrigerator for further steps.

\subsection{Preparation of $N A D E S$}

The NADES were prepared at a specific molar ratio of choline chloride to the hydrogen bonding donor as shown in Table 1 . The mixtures of choline chloride and hydrogen bonding donors at $70 \% w / w$ were mixed with $30 \% w / w$ deionized water using a magnetic stirrer at room temperature. Then, the clear solution of NADES was used as the solvent for stilbenoids extraction.

Table 1. Natural deep eutectic solvent (NADES).

\begin{tabular}{cccc}
\hline Abbreviation & Hydrogen Bonding Acceptor & Hydrogen Bonding Donor & Molar Ratio \\
\hline Ch1G2 & Choline chloride & Glycerol & $1: 2$ \\
Ch1G1 & Choline chloride & Glycerol & $1: 1$ \\
Ch1D1 & Choline chloride & Dextrose & $1: 1$ \\
Ch1S1 & Choline chloride & Sorbitol & $1: 1$ \\
Ch1C1 & Choline chloride & Citric acid & $1: 1$ \\
Ch1O1 & Choline chloride & Oxalic acid & $1: 1$ \\
Ch1M1 & Choline chloride & Malic acid & $1: 1$ \\
\hline
\end{tabular}




\subsection{Extraction}

Ground dried M. alba callus (600 mg) was extracted with different NADES (9 mL) using ultrasound-assisted extraction (UAE) at $40 \mathrm{kHz}$ for $30 \mathrm{~min}$. Then, the extract was centrifuged at $9700 \times g$. Finally, the clarified supernatant was transferred into a new tube which was protected from light and determined stilbenoids content using HPLC. To estimate the extraction efficiency of NADES compared with the conventional organic solvents, methanol and ethanol were used for M. alba callus extraction.

\subsection{Stability Study}

The stability study of stilbenoids in NADES was performed in the form of an extract and in the form of spiked stilbenoids in the blank solvents. The M. alba callus extracts were prepared as in Section 2.4 by using NADES and methanol as the solvents separately. All samples were separately kept at $4{ }^{\circ} \mathrm{C}, 30{ }^{\circ} \mathrm{C}$ and $40^{\circ} \mathrm{C}$. In the case of the extracts by methanol, the extracts were kept only at $4{ }^{\circ} \mathrm{C}$. Then, the extracts were determined to stilbenoids content at 1 and 6 months after storage. Meanwhile, in the form of a spiked sample, the standard solution of mulberroside A, oxyresveratrol and resveratrol were separately prepared in methanol. Then, the standard solution was added to each solvent (Ch1G2, Ch1M1 and methanol) at a final concentration of $25 \mu \mathrm{g} / \mathrm{mL}$.

\subsection{Determination of Stilbenoids by HPLC Analysis}

Mulberroside A, oxyresveratrol and resveratrol were used as representative stilbenoid contents in M. alba callus and determined by HPLC analysis. The HPLC procedure was modified from a previous study [14]. Briefly, the extract was diluted with methanol four times and filtered with a $0.22 \mu \mathrm{m}$ syringe filter. Then, the stilbenoid contents were analyzed using an LC-10AD HPLC system (Shimadzu, Kyoto, Japan) equipped with a Cosmosil 5 C18-MS-II $(5 \mu \mathrm{m}, 250 \mathrm{~mm} \times 4.6 \mathrm{~mm}$ I.D. $)$ column and a UV detector $(320 \mathrm{~nm})$. The elution was performed at a flow rate of $1.0 \mathrm{~mL} / \mathrm{min}$ with acidified water $(1.5 \%$ acetic acid: solvent A) and acetonitrile (solvent $\mathrm{B}$ ) with the following gradient: $6 \% \mathrm{~B}(0-2 \mathrm{~min}), 6-12 \% \mathrm{~B}$ (2-3 min), 12\% B (3-9 min), 12-18\% B (9-11 min), 18\% B (11-17 min), 18-40\% B (17-20 min), $40 \%$ B (20-25 min), 40-80\% B (25-28 min), 80-6\% B (28-32 min) and 6\% B (32-44 min). The calibration curves were generated by using five concentrations of each standard compound (1.56 to $25 \mu \mathrm{g} / \mathrm{mL}$ ). The stilbenoid contents were calculated from the peak areas.

\subsection{Anti-Melanogenesis Activity}

The anti-melanogenesis assay was performed on B16-F10 cells as in a previous study with some modifications [15]. The mouse melanoma cell line B16F10 (CRL-6475) was cultured in DMEM containing $10 \% \mathrm{FBS}$ and $1 \%$ penicillin-streptomycin solution at $37^{\circ} \mathrm{C}$ in a humidified $5 \% \mathrm{CO}_{2}$ incubator. The extracts that provide a high yield of stilbenoids were selected for study in this section. Each extract was filtered with a $0.45 \mu \mathrm{m}$ syringe filter, and then diluted with DMEM to reach a final concentration of $0.1 \%$ and $1 \%$ of the extract for testing in cell assay.

\subsubsection{Cytotoxicity Assay}

Cells were seeded at a density of 2500 cells per well of 96 -well culture plates. After overnight incubation, cells were treated with $0.1 \%$ and $1 \%$ of the extracts or $1 \mathrm{mM}$ kojic acid for 3 days with $\alpha$-MSH $(10 \mathrm{nM})$. Blank medium with $\alpha$-MSH was used as control. Cell viability was measured using the MTT assay as previously described [16]. The percentage of cell viability was calculated.

\subsubsection{Inhibitory Activity in Extracellular Melanin Production}

Cells were seeded at a density of 2500 cells per well of 96-well culture plates and incubated for $24 \mathrm{~h}$. The cells were treated with $0.1 \%$ and $1 \%$ of the extracts followed by stimulation with $\alpha$-MSH $(10 \mathrm{nM})$ for 3 days. Melanin contents in cell-free culture medium were assayed by measuring the absorbance at $405 \mathrm{~nm}$ using a microplate reader and were 
calculated from a standard curve generated using synthetic melanin. Kojic acid (1 mM) and culture media in the absence of $\alpha-\mathrm{MSH}$ were used as a positive and negative control, respectively. The percentage of melanin content was compared with negative $\alpha-\mathrm{MSH}$.

\subsection{Skin Irritation Test}

The skin irritation test was performed using reconstructed human epidermis (RhE) or EpiSkin ${ }^{\mathrm{TM}}$ with some modifications from the OECD [17]. Briefly, the skin tissue was cultured in $2 \mathrm{~mL}$ of maintenance medium in a 12 -well plate and incubated at $37{ }^{\circ} \mathrm{C}, 5 \%$ $\mathrm{CO}_{2}, 95 \% \mathrm{RH}$ for $24 \mathrm{~h}$. Then, $50 \% \mathrm{w} / \mathrm{v}$ of an extract was applied to the skin tissue and incubated for $24 \mathrm{~h}$. Whereas 5\% w/v sodium lauryl sulfate (SLS) and phosphate buffer saline (PBS) were used as positive and negative controls, respectively. After exposure, the skin tissue was washed with 10-15 mL of PBS 3 times and transferred to a new 12-well plate with $2 \mathrm{~mL}$ of maintenance medium for $42 \mathrm{~h}$ of incubation. The cell viability was then performed by the MTT assay. $2 \mathrm{~mL}$ of MTT solution $(0.3 \mathrm{mg} / \mathrm{mL})$ was added to each well. After incubation for $3 \mathrm{~h}, 500 \mu \mathrm{L}$ of acidic isopropanol was added to dissolve the formazan from the skin tissue. The supernatant was collected and measured at $570 \mathrm{~nm}$. The percentage of cell viability was calculated using Equation (1):

$$
\% \text { Cell viability }=\left(\mathrm{OD}_{\text {sample }} / \mathrm{OD}_{\text {negative control }}\right) \cdot 100
$$

\subsection{Statistical Analysis}

The data analysis was performed using PASW Statistics for Windows, version 18.0 software (SPSS Inc., Chicago, IL, USA). The data was expressed as mean \pm SD. The statistical significance between groups in the yield of stilbenoids and anti-melanogenesis activity derived from different solvents was determined using one-way analysis of variance (ANOVA) with Duncan's method ( $p$-value $<0.01$ ). The statistical significance values for the stability study were carried out using one-way ANOVA with Tukey's test ( $p$-value $<0.01)$. All experiments were performed in triplicate.

\section{Results}

In this study, the extraction efficiency of seven different NADES was investigated by measuring stilbenoids content, including mulberroside A, oxyresveratrol and resveratrol. The extraction efficiency was compared with ethanol and methanol.

In Table 2, the extraction by Ch1G2 exhibited the highest stilbenoids content $(5.06 \pm 0.05 \mathrm{mg} / \mathrm{g}$ callus dry weight) among other NADES. Moreover, it was higher than the extraction yield of ethanol $(0.81 \pm 0.04 \mathrm{mg} / \mathrm{g}$ callus dry weight). The stilbenoids yield of stilbenoids in the Ch1G2 extract was not significantly different from that in the methanol (6.32 $\pm 0.40 \mathrm{mg} / \mathrm{g}$ callus dry weight).

Table 2. Extraction yield of stilbenoids in NADES (mean $\pm \mathrm{SD}, n=3$ ).

\begin{tabular}{cccc}
\hline \multirow{2}{*}{ NADES } & \multicolumn{3}{c}{ (mg/g Callus Dry Weight) } \\
\cline { 2 - 4 } & Mulberroside A & Oxyresveratrol & Stilbenoids Content \\
\hline Ch1G2 & $4.93 \pm 0.04^{\mathrm{b}}$ & $0.13 \pm 0.01^{\mathrm{a}}$ & $5.06 \pm 0.05^{\mathrm{a}, \mathrm{b}}$ \\
Ch1G1 & $2.20 \pm 0.04^{\mathrm{e}}$ & n.d. & $2.20 \pm 0.04^{\mathrm{c}, \mathrm{d}}$ \\
Ch1D1 & $3.87 \pm 0.16^{\mathrm{c}}$ & n.d. & $3.87 \pm 0.16^{\mathrm{c}, \mathrm{d}}$ \\
Ch1S1 & $1.67 \pm 0.11^{\mathrm{f}}$ & $0.08 \pm 0.00^{\mathrm{b}}$ & $1.74 \pm 0.11^{\mathrm{d}}$ \\
Ch1C1 & $2.95 \pm 0.07^{\mathrm{d}}$ & n.d. & $2.95 \pm 0.07^{\mathrm{c}}$ \\
Ch1O1 & $0.89 \pm 0.04^{\mathrm{g}}$ & $0.05 \pm 0.01^{\mathrm{b}}$ & $0.94 \pm 0.05^{\mathrm{d}}$ \\
Ch1M1 & $3.82 \pm 0.08^{\mathrm{c}}$ & $0.13 \pm 0.01^{\mathrm{a}}$ & $3.95 \pm 0.08^{\mathrm{b}, \mathrm{c}}$ \\
Ethanol & $0.81 \pm 0.04^{\mathrm{g}}$ & n.d. & $0.81 \pm 0.04^{\mathrm{d}}$ \\
Methanol & $6.14 \pm 0.37^{\mathrm{a}}$ & $0.17 \pm 0.04^{\mathrm{a}}$ & $6.32 \pm 0.40^{\mathrm{a}}$ \\
\hline
\end{tabular}

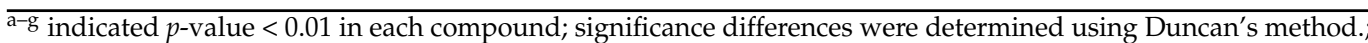
n.d. $=$ not detected 
To determine the skin lightening properties of the M. alba callus extracts from NADES, anti-melanogenesis activity in B16-F10 melanoma was investigated. According to the stilbenoid yield, the extracts derived from Ch1G2, Ch1D1, Ch1M1 were chosen for the anti-melanogenesis activity investigation. By exhibiting greater than $80 \%$ cell viability, all test samples demonstrate no cytotoxicity (Figure 1). In terms of anti-melanogenesis activity, at the concentration of $1 \%$ of M. alba callus extracts from Ch1G2, Ch1D1, Ch1M1 and methanol revealed a significant decrease in melanin content when stimulated by $\alpha-\mathrm{MSH}$ (Figure 2).

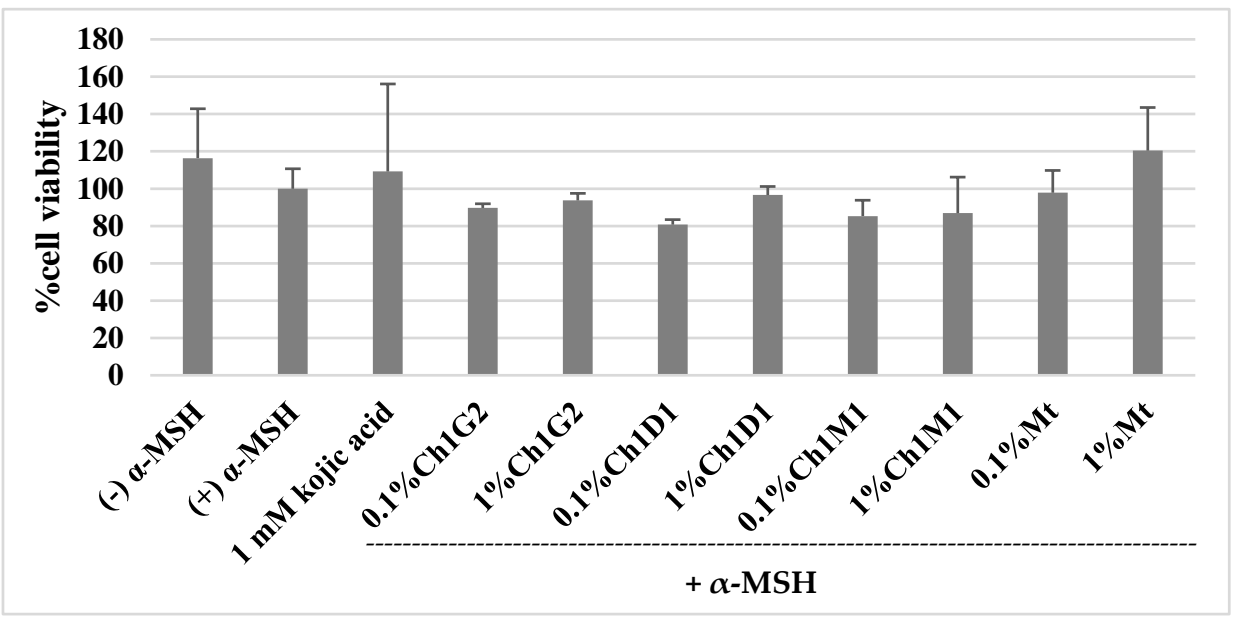

Figure 1. Percentage of cell viability of B16-F10 melanoma after treatment with kojic acid (positive control), NADES and methanol (MT) extracts of M. alba in the presence (+) or absence (-) of $\alpha$-MSH $(10 \mathrm{nM})($ mean $\pm \mathrm{SD}, n=3)$.

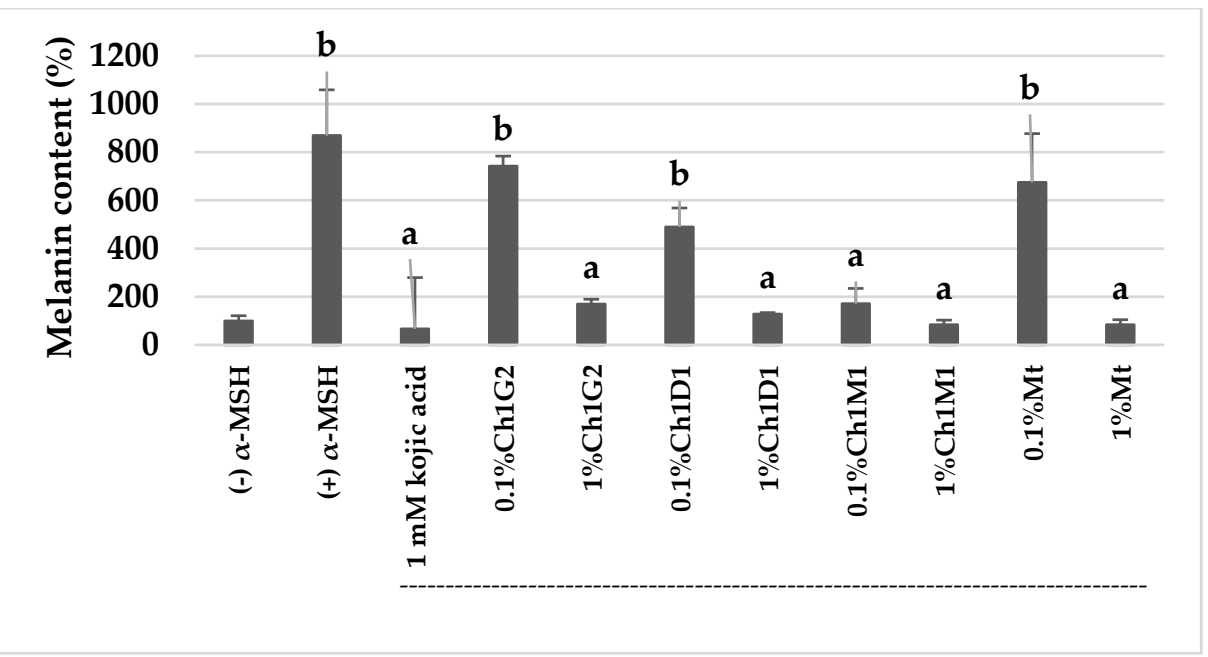

Figure 2. The percentage of extracellular melanin content from B16-F10 melanoma after treatment with kojic acid (positive control), NADES and methanol (MT) extracts of M. alba in the presence (+) or absence ( - ) of $\alpha$-MSH (10 nM) (mean $\pm \mathrm{SD}, n=3)$, a,b indicated $p$-value $<0.01$ among positive $\alpha$-MSH groups; significance differences were determined using Duncan's method.

Consequently, the extracts derived from Ch1G2 and Ch1M1 were chosen to perform the stability test in comparison with the methanol extract. The extracts were stored for 1 and 6 months at $4{ }^{\circ} \mathrm{C}, 30^{\circ} \mathrm{C}$ and $40^{\circ} \mathrm{C}$ except the methanol extract, which was stored only at $4{ }^{\circ} \mathrm{C}$ due to its low flash point $\left(9-12{ }^{\circ} \mathrm{C}\right)$. After storage, the remaining stilbenoids were measured by HPLC (Table 3). The results showed that mulberroside A content in the extract derived from Ch1G2 was stable for 1 month at every storage temperature and more stable after 6-month storage, in comparison with Ch1M1. The content of mulberroside A in 
the extracts derived from Ch1M1 and methanol obviously decreased at 1 and 6 months. The low levels of oxyresveratrol were detected in the samples and it was not stable in all types of tested solvents except methanol at $4{ }^{\circ} \mathrm{C}$ for 1 month. Resveratrol could not be detected in the extracts.

Table 3. The stability of stilbenoids in MA extract using NADES and methanol at varying temperatures for 1 and 6 months (mean $\pm \mathrm{SD}, n=3$ ).

\begin{tabular}{|c|c|c|c|c|}
\hline \multicolumn{2}{|c|}{ Solvents } & Ch1G2 & Ch1M1 & Methanol \\
\hline \multicolumn{2}{|c|}{$4{ }^{\circ} \mathrm{C}$} & \multicolumn{3}{|c|}{$\mathrm{mg} / \mathrm{g}$ callus dry weight } \\
\hline \multirow{3}{*}{$\begin{array}{l}\text { Mulberroside A } \\
\text { (mg/g) }\end{array}$} & 0 month & $4.93 \pm 0.04$ & $3.82 \pm 0.08$ & $6.14 \pm 0.37$ \\
\hline & 1 month & $4.74 \pm 0.06$ & $2.62 \pm 0.17^{*}$ & $5.32 \pm 0.16$ * \\
\hline & 6 months & $4.65 \pm 0.09 *$ & $2.94 \pm 0.03 *$ & $5.28 \pm 0.03 *$ \\
\hline \multirow{3}{*}{$\begin{array}{l}\text { Oxyresveratrol } \\
(\mathrm{mg} / \mathrm{g})\end{array}$} & 0 month & $0.13 \pm 0.01$ & $0.13 \pm 0.01$ & $0.17 \pm 0.04$ \\
\hline & 1 month & $0.09 \pm 0.00 *$ & n.d. & $0.11 \pm 0.00$ \\
\hline & 6 months & $0.05 \pm 0.01$ * & n.d. & $0.07 \pm 0.00 *$ \\
\hline \multicolumn{5}{|c|}{$30{ }^{\circ} \mathrm{C}$} \\
\hline \multirow{3}{*}{$\begin{array}{l}\text { Mulberroside A } \\
(\mathrm{mg} / \mathrm{g})\end{array}$} & 0 month & $4.93 \pm 0.04$ & $3.82 \pm 0.08$ & - \\
\hline & 1 month & $4.75 \pm 0.12$ & $2.71 \pm 0.11 *$ & \\
\hline & 6 months & $2.15 \pm 0.00 *$ & $2.32 \pm 0.02 *$ & -- \\
\hline \multirow{3}{*}{$\begin{array}{l}\text { Oxyresveratrol } \\
(\mathrm{mg} / \mathrm{g})\end{array}$} & 0 month & $0.13 \pm 0.01$ & $0.13 \pm 0.01$ & - \\
\hline & 1 month & n.d. & n.d. & \\
\hline & 6 months & n.d. & n.d. & -- \\
\hline \multicolumn{5}{|c|}{$40^{\circ} \mathrm{C}$} \\
\hline \multirow{3}{*}{$\begin{array}{l}\text { Mulberroside A } \\
(\mathrm{mg} / \mathrm{g})\end{array}$} & 0 month & $4.93 \pm 0.04$ & $3.82 \pm 0.08$ & - \\
\hline & 1 month & $5.15 \pm 0.31$ & $1.74 \pm 0.07 *$ & \\
\hline & 6 months & $3.18 \pm 0.03 *$ & n.d. & - \\
\hline \multirow{3}{*}{$\begin{array}{l}\text { Oxyresveratrol } \\
\text { (mg/g) }\end{array}$} & 0 month & $0.13 \pm 0.01$ & $0.13 \pm 0.01$ & - \\
\hline & 1 month & n.d. & n.d. & \\
\hline & 6 months & n.d. & n.d. & - \\
\hline
\end{tabular}

Due to the small amount of oxyresveratrol and resveratrol found in the extracts, the stability study was performed using standard spiking of oxyresveratrol, resveratrol, and mulberroside A into Ch1G2, Ch1M1 and methanol to clarify the individual stability of each stilbenoid. The study was also performed under the same temperatures and storage time conditions. In Ch1G2 and methanol, mulberroside A and oxyresveratrol content persisted more than $90 \%$ and $70 \%$, respectively, for 6 months at $4{ }^{\circ} \mathrm{C}$ (Table 4 ). The mulberroside A content remained more than $90 \%$ in $\mathrm{Ch} 1 \mathrm{G} 2$ at $40{ }^{\circ} \mathrm{C}$. All of the spiked stilbenoids in Ch1M1 decreased in content, which was related to the increase in temperature and storage time.

To ensure the safety of leave-on products, the skin irritation test was evaluated using an extract derived from a choline chloride-based NADES. Due to the high yield and stability of stilbenoids in Ch1G2, the M. alba callus extract derived from Ch1G2 was selected to investigate its skin irritation effects.

The 50\% w/v M. alba callus extract derived from Ch1G2 (MA-Ch1G2), containing approximately $15 \% w / v$ of choline chloride, was applied on a reconstructed human epidermis model. The skin irritation test results were expressed as a percentage of cell viability compared with PBS and 5\% w/v SLS as negative and positive controls, respectively. In Figure 3, the percentage of cell viability of MA-Ch1G2 was $82.36 \%$ which is categorized as safe according to the OECD guideline. Thus, 50\% w/v MA-Ch1G2 or its lower concentration can be readily applied in cosmetic formulations without skin irritation effect. 
Table 4. The stability of added stilbenoids in NADES and methanol at varying temperatures for 1 and 6 months (mean $\pm \mathrm{SD}, n=3$ ).

\begin{tabular}{|c|c|c|c|c|}
\hline \multicolumn{2}{|c|}{ DES } & Ch1G2 & Ch1M1 & Methanol \\
\hline \multicolumn{2}{|c|}{$4{ }^{\circ} \mathrm{C}$} & \multicolumn{3}{|c|}{$\begin{array}{c}\mu \mathrm{g} / \mathrm{mL} \\
\text { (Percentage of residue content) }\end{array}$} \\
\hline Mulberroside A & $\begin{array}{l}1 \text { month } \\
6 \text { months }\end{array}$ & $\begin{array}{c}24.80 \pm 0.48 \\
(99.20 \%) \\
23.08 \pm 0.80 \\
(92.32 \%)\end{array}$ & $\begin{array}{c}20.20 \pm 0.96 \\
(80.80 \%) \\
16.88 \pm 0.40 \\
(67.52 \%)\end{array}$ & $\begin{array}{c}24.92 \pm 1.80 \\
(99.68 \%) \\
24.24 \pm 1.08 \\
(96.96 \%)\end{array}$ \\
\hline $\begin{array}{l}\text { Oxyresveratrol } \\
\quad(\mu \mathrm{g} / \mathrm{mL})\end{array}$ & $\begin{array}{l}1 \text { month } \\
6 \text { months }\end{array}$ & $\begin{array}{c}17.52 \pm 0.24 \\
(70.08 \%) \\
17.56 \pm 0.64 \\
(70.24 \%)\end{array}$ & $\begin{array}{c}15.80 \pm 0.52 \\
(63.20 \%) \\
13.12 \pm 0.32 \\
(52.48 \%)\end{array}$ & $\begin{array}{c}19.68 \pm 0.92 \\
(78.72 \%) \\
17.84 \pm 0.40 \\
(71.36 \%)\end{array}$ \\
\hline $\begin{array}{l}\text { Resveratrol } \\
(\mu \mathrm{g} / \mathrm{mL})\end{array}$ & $\begin{array}{l}1 \text { month } \\
6 \text { months }\end{array}$ & $\begin{array}{c}16.08 \pm 0.44 \\
(64.2 \%) \\
17.96 \pm 0.72 \\
(71.84 \%)\end{array}$ & $\begin{array}{c}16.00 \pm 1.52 \\
(64.00 \%) \\
13.88 \pm 0.52 \\
(55.52 \%)\end{array}$ & $\begin{array}{c}23.40 \pm 1.48 \\
(93.60 \%) \\
20.00 \pm 1.60 \\
(80.00 \%)\end{array}$ \\
\hline \multicolumn{5}{|c|}{$30{ }^{\circ} \mathrm{C}$} \\
\hline $\begin{array}{l}\text { Mulberroside A } \\
(\mu \mathrm{g} / \mathrm{mL})\end{array}$ & $\begin{array}{l}1 \text { month } \\
6 \text { months }\end{array}$ & $\begin{array}{c}20.12 \pm 0.24 \\
(80.48 \%) \\
22.24 \pm 0.48 \\
(88.96 \%)\end{array}$ & $\begin{array}{c}13.76 \pm 0.88 \\
(55.04 \%) \\
10.76 \pm 0.52 \\
(43.04 \%)\end{array}$ & - \\
\hline $\begin{array}{l}\text { Oxyresveratrol } \\
(\mu \mathrm{g} / \mathrm{mL})\end{array}$ & $\begin{array}{l}1 \text { month } \\
6 \text { months }\end{array}$ & $\begin{array}{c}15.04 \pm 0.28 \\
(60.16 \%) \\
7.68 \pm 0.08 \\
(30.72 \%)\end{array}$ & $\begin{array}{c}13.32 \pm 0.44 \\
(53.28 \%) \\
3.36 \pm 0.04 \\
(13.44 \%)\end{array}$ & - \\
\hline $\begin{array}{l}\text { Resveratrol } \\
(\mu \mathrm{g} / \mathrm{mL})\end{array}$ & $\begin{array}{l}1 \text { month } \\
6 \text { months }\end{array}$ & $\begin{array}{c}15.80 \pm 1.20 \\
(63.20 \%) \\
14.84 \pm 0.60 \\
(59.36 \%)\end{array}$ & $\begin{array}{c}14.08 \pm 0.88 \\
(56.32 \%) \\
9.80 \pm 0.08 \\
(39.20 \%)\end{array}$ & $\begin{array}{l}- \\
-\end{array}$ \\
\hline \multicolumn{5}{|c|}{$40{ }^{\circ} \mathrm{C}$} \\
\hline $\begin{array}{l}\text { Mulberroside A } \\
(\mu \mathrm{g} / \mathrm{mL})\end{array}$ & $\begin{array}{l}1 \text { month } \\
6 \text { months }\end{array}$ & $\begin{array}{c}23.68 \pm 1.28 \\
(94.72 \%) \\
23.56 \pm 0.28 \\
(94.24 \%)\end{array}$ & $\begin{array}{c}8.96 \pm 0.44 \\
(35.84 \%) \\
\text { n.d. } \\
-\end{array}$ & $\begin{array}{l}- \\
-\end{array}$ \\
\hline $\begin{array}{l}\text { Oxyresveratrol } \\
\quad(\mu \mathrm{g} / \mathrm{mL})\end{array}$ & $\begin{array}{l}1 \text { month } \\
6 \text { months }\end{array}$ & $\begin{array}{c}17.08 \pm 0.76 \\
(68.32 \%) \\
\text { n.d. } \\
-\end{array}$ & $\begin{array}{c}9.80 \pm 0.16 \\
(39.20 \%) \\
\text { n.d. } \\
-\end{array}$ & - \\
\hline $\begin{array}{l}\text { Resveratrol } \\
(\mu \mathrm{g} / \mathrm{mL})\end{array}$ & $\begin{array}{l}1 \text { month } \\
6 \text { months }\end{array}$ & $\begin{array}{c}17.28 \pm 1.00 \\
(69.12 \%) \\
5.76 \pm 0.12 \\
(23.04 \%)\end{array}$ & $\begin{array}{c}12.56 \pm 1.04 \\
(50.24 \%) \\
\text { n.d. } \\
-\end{array}$ & - \\
\hline
\end{tabular}




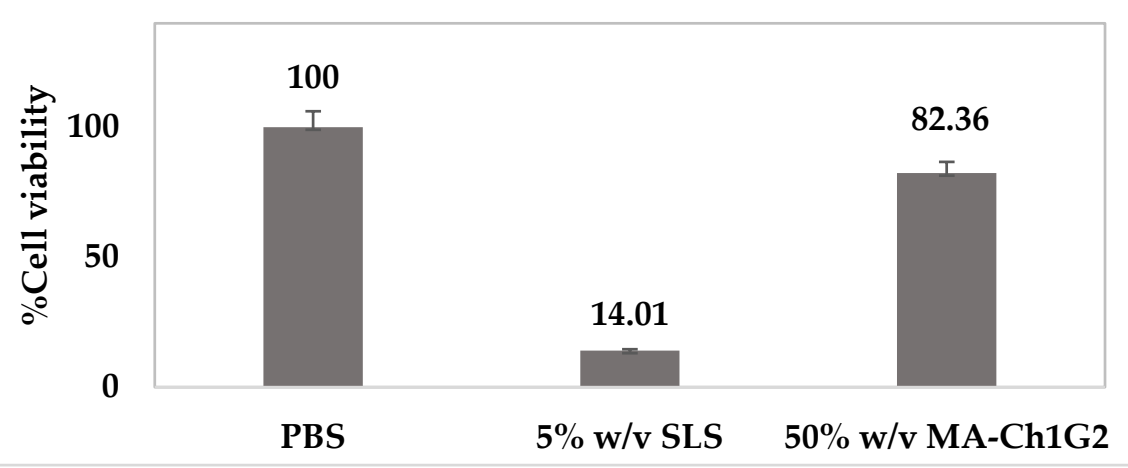

Figure 3. The percentage of cell viability after treatment with $50 \% w / v$ M. alba callus extracts from Ch1G2 (MA-Ch1G2), PBS and 5\% w/v SLS as negative and positive controls, respectively. (mean $\pm \mathrm{SD}, n=3$ ).

\section{Discussion}

\subsection{Capacity of NADES for M. alba Callus Extraction}

NADES have been used to increase the solubility and stability of compounds that are hydrophobic and to conduct novel sustainable and green extractions. Combining NADES and biotechnology enables the production of a unique active ingredient for cosmetics while maintaining an economically viable and sustainable process [11,12].

To achieve an effective extraction method, popular techniques such as microwaveassisted and ultrasound-assisted extraction have been frequently used in combination with NADES $[8,11]$. However, our preliminary study found that microwave-assisted extraction altered the conformation of stilbenoids in the M. alba callus extract, causing a change to their less effective cis-forms (data not shown). As a result, this study employed ultrasound-assisted extraction.

The most intriguing result in our study came from the extraction with a mixture of choline chloride and glycerol (Ch1G2), which extracted stilbenoids with a yield comparable to that of methanol extraction and acceptable stilbenoid stability. Similarly, in earlier reports choline chloride-based NADES exhibited efficiency in extracting phenolic compounds [18,19]. According to the results of a skin irritation test, Ch1G2 is safe for leave-on cosmetics. In further study, the compatibility of NADES in cosmetic formulations is required to complete the overall information.

\subsection{Stilbenoids Content and Anti-Melanogenesis Activity}

Previously, it was suggested that urea-glycerol-based NADES was a viable option for extracting oxyresveratrol from M. alba roots [20]. However, to obtain a variety of active compounds with anti-melanogenesis activity from M. alba callus, this study used a choline chloride-glycerol-based NADES.

The Ch1G2 extract of M. alba callus contained a high stilbenoid yield and exhibited good anti-melanogenesis activity. The stilbenoid content is probably a good bioactivity marker for M. alba callus extracts. However, those of the Ch1M1 extract were contrary. The extraction with Ch1M1 provided a low stilbenoid content in comparison with methanol (Table 2), while the $0.1 \%$ of Ch1M1 extract showed the highest anti-melanogenesis activity compared with the same concentration of other solvents. This could be due to synergistic effects of non-stilbenoid compounds, including malic acid within the solvent. Malic acid is one of the $\alpha$-hydroxy acids (AHAs) which have been reported to be effective in treating hyperpigmentation. The underlying mechanism of the anti-melanogenesis activity of malic acid is still not clear. Some AHAs, such as glycolic acid and lactic acid, have been reported to suppress melanin formation by directly inhibiting tyrosinase activity, which might be possible in malic acid [21,22]. Although Ch1M1 is not suitable for the extraction of $M$. alba stilbenoids, it could have potential to extract other non-stilbenoid compounds with 
anti-melanogenesis properties. Our findings corroborate previous reports that NADES can be optimized to extract compounds with a range of polarity degrees [23].

The capacity of a mixture of choline chloride and glycerol to extract stilbenoids in this study is consistent with a previous report on stilbenoids extraction in peanuts [13]. The information may be further applied to the extraction of stilbenoids from other plants, such as Artocarpus lacucha. However, due to the small amount of resveratrol in M. alba callus, it was not detected from the extracts in all types of solvent in this study. In an earlier study, M. alba callus was reported to contain only a small amount of resveratrol, which required elicitation or post-harvest treatment to increase [14]. In nature, the roots of M. alba also show a variation in stilbenoids content in different cultivation regions [24]. Besides that, stilbenoids content might depend on the cultivation batch, variation in culture or harvesting process [25].

\subsection{Stilbenoids Stability}

The stilbenoids stability in the selected NADES was clarified by stilbenoids spiking. Although the spiked resveratrol content in methanol was more than $90 \%$ stable at $4{ }^{\circ} \mathrm{C}$ for 1 month, the flammability and toxicity of methanol limit the direct application of the extract in cosmetic formulations [26]. Consequently, conventional organic solvents must be eliminated and the limit of solvent residues ensured as indicated by the pharmaceutical or cosmetic products regulations [27]. Therefore, Ch1G2 could be an alternative instead, which should be stored at $4{ }^{\circ} \mathrm{C}$ to preserve the stilbenoid content (70-90\%) for six months.

The extract prepared using the optimal NADES demonstrates its potential as a readyto-use extract. However, because cosmetics should be stable for at least two years, additional development would be beneficial. To increase the stability of stilbenoids, stabilizers such as antioxidants and photoprotective agents might be added to the extract or finished products [28]. Additionally, to modify the stilbenoid extract, stabilization techniques such as nanocarriers may be used [29]. These could be interesting and branching strategies for synergistically increasing the stability and bioactive efficiency of stilbenoids to establish novel products.

\section{Conclusions}

This study demonstrated the extraction yields and the variable stability of stilbenoids in NADES extracts. The capacity of Ch1G2 to extract stilbenoids from M. alba callus was determined to be superior to that of six other NADES and comparable to that of methanol. Additionally, the Ch1G2 extract of M. alba callus is non-irritating. The extraction capacity and safety of the Ch1G2 extract indicated that Ch1G2 could be preferable for cosmetic use. Combining NADES extraction with in vitro cultivation of $M$. alba exemplified that sustainable extraction could be achievable.

Author Contributions: Conceptualization, T.K. and W.P.; methodology, T.K. and J.K.; software, T.K.; validation, T.K.; formal analysis, T.K. and J.K.; investigation, T.K. and J.K.; resources, W.P., J.K., T.K. and S.M.; data curation, T.K. and W.P.; writing—original draft preparation, T.K. and J.K.; writing—review and editing, T.K., W.P. and J.K.; visualization, T.K.; supervision, W.P. and S.M.; project administration, T.K.; funding acquisition, T.K. All authors have read and agreed to the published version of the manuscript.

Funding: This research was funded by the Thailand Research Fund and Office of the Higher Education Commission, grant number MRG6280161.

Institutional Review Board Statement: Not applicable.

Informed Consent Statement: Not applicable.

Data Availability Statement: Not applicable.

Acknowledgments: This work was conducted and supported by Faculty of Pharmacy, Mahidol University, Bangkok, Thailand.

Conflicts of Interest: The authors declare no conflict of interest. 


\section{References}

1. Chemat, F.; Abert-Vian, M.; Fabiano-Tixier, A.S.; Strube, J.; Uhlenbrock, L.; Gunjevic, V.; Cravotto, G. Green extraction of natural products. Origins, current status, and future challenges. Trends Anal. Chem. 2019, 118, 248-263. [CrossRef]

2. Abbott, A.P.; Capper, G.; Davies, D.L.; Rasheed, R.K.; Tambyrajah, V. Novel solvent properties of choline chloride/urea mixtures. Chem. Commun. 2003, 7, 70-71. [CrossRef] [PubMed]

3. Paiva, A.; Craveiro, R.; Aroso, I.; Martins, M.; Reis, R.L.; Duarte, A.R.C. Natural Deep Eutectic Solvents-Solvents for the 21st Century. ACS Sustain. Chem. Eng. 2014, 2, 1063-1071. [CrossRef]

4. Choi, Y.H.; van Spronsen, J.; Dai, Y.; Verberne, M.; Hollmann, F.; Arends, I.W.; Witkamp, G.J.; Verpoorte, R. Are natural deep eutectic solvents the missing link in understanding cellular metabolism and physiology? Plant Physiol. 2011, 156, 1701-1705. [CrossRef] [PubMed]

5. Dai, Y.; van Spronsen, J.; Witkamp, G.J.; Verpoorte, R.; Choi, Y.H. Natural deep eutectic solvents as new potential media for green technology. Anal. Chim. Acta 2013, 766, 61-68. [CrossRef] [PubMed]

6. Fernández, M.L.Á.; Espino, M.; Gomez, F.J.V.; Silva, M.F. Novel approaches mediated by tailor-made green solvents for the extraction of phenolic compounds from agro-food industrial by-products. Food Chem. 2018, 239, 671-678. [CrossRef]

7. González, C.G.; Mustafa, N.R.; Wilson, E.G.; Verpoorte, R.; Choi, Y.H. Application of natural deep eutectic solvents for the "green"extraction of vanillin from vanilla pods. Flavour Fragr. J. 2018, 33, 91-96. [CrossRef]

8. Doldolova, K.; Bener, M.; Lalikoğlu, M.; Aşçı, Y.S.; Arat, R.; Apak, R. Optimization and modeling of microwave-assisted extraction of curcumin and antioxidant compounds from turmeric by using natural deep eutectic solvents. Food Chem. 2021, $353,129337$. [CrossRef]

9. Sun, B.; Zheng, Y.L.; Yang, S.K.; Zhang, J.R.; Cheng, X.Y.; Ghiladi, R.; Ma, Z.; Wang, J.; Deng, W.W. One-pot method based on deep eutectic solvent for extraction and conversion of polydatin to resveratrol from Polygonum cuspidatum. Food Chem. 2021, 343, 128498. [CrossRef]

10. Dai, Y.; Rozema, E.; Verpoorte, R.; Choi, Y.H. Application of natural deep eutectic solvents to the extraction of anthocyanins from Catharanthus roseus with high extractability and stability replacing conventional organic solvents. J. Chromatogr. A 2016, 1434, 50-56. [CrossRef]

11. Jeong, K.M.; Ko, J.; Zhao, J.; Jin, Y.; Yoo, D.E.; Han, S.Y.; Lee, J. Multi-functioning deep eutectic solvents as extraction and storage media for bioactive natural products that are readily applicable to cosmetic products. J. Clean. Prod. 2017, 151, 87-95. [CrossRef]

12. Huang, Y.; Yang, J.; Zhao, Y.; Yu, L.; He, Y.; Wan, H.; Li, C. Screening, optimization, and bioavailability research of natural deep eutectic solvent extracts from Radix Pueraria. Molecules 2021, 26, 729. [CrossRef] [PubMed]

13. Chen, J.; Jiang, X.; Yang, G.; Bi, Y.; Liu, W. Green and efficient extraction of resveratrol from peanut roots using deep eutectic solvents. J. Chem. 2018, 4091930, 1-9.

14. Komaikul, J.; Kitisripanya, T.; Likhitwitayawuid, K.; Sritularak, B.; Tanaka, H.; Putalun, W. Improvement of stilbenoid production by 2-hydroxypropyl- $\beta$-cyclodextrin in white mulberry (Morus alba L.) callus cultures. Nat. Prod. Res. 2019, 33, 2762-2769. [CrossRef] [PubMed]

15. Kim, B.H.; Park, K.C.; Park, J.H.; Lee, C.G.; Ye, S.K.; Park, J.Y. Inhibition of tyrosinase activity and melanin production by the chalcone derivative 1-(2-cyclohexylmethoxy-6-hydroxy-phenyl)-3-(4-hydroxymethyl-phenyl)-propenone. Biochem. Biophys. Res. Commun. 2016, 480, 648-654. [CrossRef]

16. Tanticharakunsiri, W.; Mangmool, S.; Wongsariya, K.; Ochaikul, D. Characteristics and upregulation of antioxidant enzymes of kitchen mint and oolong tea kombucha beverages. J. Food Biochem. 2021, 45, e13574. [CrossRef]

17. OECD. Guideline for the Testing of Chemicals, No.439, In Vitro Skin Irritation: Reconstructed Human Epidermis Test Method. Available online: https:/ / www.oecd-ilibrary.org/docserver/9789264242845-en.pdf?expires=1628777920\&id=id\&accname= guest\&checksum=338F044AE7A8325B23AA0416C2D14217 (accessed on 12 August 2021).

18. Ivanović, M.; Albreht, A.; Krajnc, P.; Vovk, I.; Islamčević Razboršek, M. Sustainable ultrasound-assisted extraction of valuable phenolics from inflorescences of Helichrysum arenarium L. using natural deep eutectic solvents. Ind. Crops Prod. 2021, 160, 113102. [CrossRef]

19. Islamčević Razboršek, M.; Ivanović, M.; Krajnc, P.; Kolar, M. Choline chloride based natural deep eutectic solvents as extraction media for extracting phenolic compounds from chokeberry (Aronia melanocarpa). Molecules 2020, 25, 1619. [CrossRef]

20. Alishlah, T.; Mun'im, A.; Jufri, M. Optimization of urea-glycerin based nades-uae for oxyresveratrol extraction from Morus alba roots for preparation of skin whitening lotion. J. Young Pharm. 2019, 11, 155-160. [CrossRef]

21. Usuki, A.; Ohashi, A.; Sato, H.; Ochiai, Y.; Ichihashi, M.; Funasaka, Y. The inhibitory effect of glycolic acid and lactic acid on melanin synthesis in melanoma cells. Exp. Dermatol. 2003, 12 (Suppl. 2), 43-50. [CrossRef]

22. Couteau, C.; Coiffard, L. Overview of skin whitening agents: Drugs and cosmetic products. Cosmetics 2016, 3, 27. [CrossRef]

23. Ivanović, M.; Islamčević Razboršek, M.; Kolar, M. Innovative extraction techniques using deep eutectic solvents and analytical methods for the isolation and characterization of natural bioactive compounds from plant material. Plants 2020, 9, 1428. [CrossRef] [PubMed]

24. Piao, S.J.; Chen, L.X.; Kang, N.; Qiu, F. Simultaneous determination of five characteristic stilbene glycosides in root bark of Morus albus L. (Cortex Mori) using high-performance liquid chromatography. Phytochem. Anal. 2011, 22, 230-235. [CrossRef] [PubMed] 
25. Komaikul, J.; Kitisripanya, T.; Inyai, C.; Likhitwitayawuid, K.; Sritularak, B.; Tanaka, H.; Putalun, W. Phytostilbenoid production in white mulberry (Morus alba L.) cell culture using bioreactors and simple deglycosylation by endogenous enzymatic hydrolysis. Vitro Cell. Dev. Biol.-Plant 2019, 55, 199-208. [CrossRef]

26. Mohamed, M. Green, environment-friendly, analytical tools give insights in pharmaceuticals and cosmetics analysis. Trends Anal. Chem. 2015, 66, 176-192. [CrossRef]

27. Yi, X.; Guo, D.; Deng, X.; Li, B.; Fan, X.; Zhu, J. Determination of methanol in cosmetics by headspace and multidimensional gas chromatography with mass spectrometric detection. J. AOAC Int. 2011, 94, 655-659. [CrossRef]

28. Tian, B.; Liu, J. Resveratrol: A review of plant sources, synthesis, stability, modification and food application. J. Sci. Food Agric. 2020, 100, 1392-1404. [CrossRef]

29. Szulc-Musioł, B.; Sarecka-Hujar, B. The use of micro-and nanocarriers for resveratrol delivery into and across the skin in different skin diseases-A literature review. Pharmaceutics 2021, 13, 451. [CrossRef] 